\section{O ENSINO} DA QUÍMICA NA DÉCADA DE 80: alguns contributos da teoria da aprendizagem e da epistemologia ${ }^{\prime}\left({ }^{2}\right)$

Durante a década de 50 e nos primeiros anos da década de 60 , realizei estudos em Ciências e em educação enquanto ensinava botânica e biologia na Universidade de Minnesota, Kansas State College e na Universidade de Pardue. Os meus estudos em educação foram frustrantes na medida em que as instruçðes que encontrei para o ensino se baseavam amplamente em práticas usualmente empregues por "professores experientes» mais do que numa evidência baseada num corpo de pesquisa em conjugação com principios orientadores e teorias. Procurando uma teoria de referência para orientar os nossos estudos e a instrução, os meus estudantes graduados e eu próprio utilizámos princípios da cibernética (Wiener, $1948,1954)$ e focámos os nossos esforços no estudo da resolução de problemas («problem solving»). Em 1963 começamos a notar inconsistências entre os nossos dados e o que tínhamos predicto com base na teoria. Com a publicação da obra de Ausubel The Psycology of Meaningful Verbal Learning (1968), começámos a utilizar a sua teoria para orientar o nosso trabalho, e posteriormente para desenvolver a teoria (Ausubel, Novak e Hanesian, 1978).

As ideias de Conant (1947) sobre a forma como os cientistas produzem o conhecimento e as raizes históricas dos conceitos contemporâneos foram também úteis para mim nos meus primeiros trabalhos, mas o livro de Kuhn (1962) Structure of Scientific Revolutions e mais tarde os escritos de Toulmin (1972) foram muito mais úteis ao mostrarem as relaçðes entre conceitos (ou paradigmas) e a resolução de problemas em ciência. A epistemologia de Kuhn e Toulmin também deram apoio à importância de uma teoria de aprendizagem focada na natureza e no papel dos conceitos (em contraste com as concepçð̃es de alteração comportamental de Skinner). A teoria de aprendizagem de Ausubel tomou um significado e importância crescentes para o nosso trabalho.

A teoria de Ausubel é simultaneamente simples e óbvia bem como profunda e subtil. Na epigrafe do seu livro, Ausubel afirma:

Se tivesse que sintetizar toda a psicologia educacional num único princípio, eu diria: o factor mais importante que influencia a aprendizagem é o que o aluno já sabe. Assegurem-se disso e ensinem em conformidade.

A simplicidade reside no facto de que todos nós sabemos que «devemos começar onde o aluno se encon-
Joseph D. Novak, Cornell University

tra», mas o que a teoria de Ausubel tem de profundo são os princípios que ele estabeleceu para nos guiar no processo de "ensinar em conformidade». Os sete princípios chave na teoria de Ausubel estão indicados na fig. 1.

A ideia mais importante na teoria de Ausubel é o conceito de "aprendizagem com significado». («meaningful learning»). Com isto, Ausubel quer descrever a aprendizagem em que novos conhecimentos são incorporados (assimilados) em conceitos relevantes que o aluno já possui( ${ }^{3}$ ). Uma vez que o curso da experiência que cada pessoa teve conduzindo à aquisição de conceitos é única, cada aluno tem um conjunto idiosincrático de conceitos que Ausubel chama conceitos integrados («subsuming concepts»). Os conceitos que cada um de nós tem são partilhados por todos («commonality») num grau que nos permite usar rótulos de linguagem para comunicar uns com os outros.

No entanto, os rótulos («labels») dos conceitos são sempre idiosincraticamente interpretados pelo aluno. $\mathrm{O}$ meu conceito de molécula não é exactamente o mesmo que o vosso e o mesmo se passa com o meu conceito do que é um conceito. Definirei conceito como a regularidade em acontecimentos ou objectos designados por um sinal ou símbolo para focar a essência do significado que queremos transmitir, especialmente nas ciências.

Podemos aprender de cor a definição dum conceito; por exemplo, que uma molécula são dois ou mais átomos ligados entre si, mas esta regularidade apenas se torna significativa se nós incorporarmos o significado deste conceito nos nossos conceitos de dois, mais, fatomos, ligação entre si.

É claro que estes últimos conceitos têm um significado diferente para o químico e para o estudante principiante. Por causa da grande variedade dos significados

(1) Tradução de Ana Laura Araújo e Vitor Duarte Teodoro. Agradece-se os esclarecimentos prestados pela Prof. Dr. Maria Odete Valente, acerca de alguns termos utilizados pelo autor.

(2) Preparado para o Swedish National Board of Universities and Colleges and the Coordinating Committee for Training University Teachers. Janeiro, 1980.

(3) Isto levanta sempre a questão de saber onde é que o aluno adquire os primeiros conceitos e Ausubel descreve este processo de formação de conceitos («concept formation») que ocorre fundamentalmente nos anos pré-escolares. 


\section{APRENDIZAGEM DURADOURA SEGUNDO A TEORIA DE AUSUBEL}

1. Aprendizagem com significado - os novos conhecimentos são conscientemente ancorados em conceitos (relevantes, específicos e existentes anteriormente) e proposiçð̃es da estrutura cognitiva e incorporados nestes conceitos.

A aprendizagem move-se de baixo para cima no contínuo aprendizagem rotineira - aprendizagem com significado quando os processos seguintes são facilitados.

3. Integração - incorporação do novo conhecimento em conceitos específicos relevantes ou em proposiçøes.

4. Reconciliação integrativa - nova aprendizagem que resulta na delineação explícita das semelhanças e diferenças entre conceitos relacionados mutuamente. aprendizagem com significado

5. Aprendizagem de ordem superior novos conceitos ou proposiçðes adquiridos que relacionem os significados de duas ou mais ideias relacionadas de menor generalidade.

6. Diferenciação progressiva - elaboração e clarificação dos significados de conceitos ou proposiçøes que ocorrem no tempo quando nova interiorização, reconciliação integrativa e/ou aprendizagem de ordem superior ocorre.

7. Organizador inicial - uma breve tarefa de aprendizagem com significado destinada a ajudar o aluno a ancorar novo conhecimento específico em conceitos relevantes ou proposiçð̃es que ele já sabe.

2. Aprendizagem rotineira - incorporação arbitrária e literal de nova informação na estrutura cognitiva.

Fig. 1. Sete conceitos-chave na teoria de Ausubel para aprendizagem no dominio cognitivo que necessitam ser considerados para facilitar a aprendizagem com significado. A aprendizagem torna-se menos rotineira e mais significativa quando a instruçào é planeada para encorajar integraçào, reconciliaçào integrativa, aprendizagem de ordem superior e diferenciaça

relevantes, das suas ligações com outros conceitos e das diversas disposições do aluno para assimilar o novo conhecimento nos conceitos existentes, a aprendizagem é um continuum do decorar quase puro até ao altamente significativo.

Para o químico, no entanto, as questoes-chave são determinar quais os conceitos que os meus alunos já conhecem e que eu posso usar para neles «ancorar" conhecimentos novos, e como devo eu dar sequência ao meu ensino, de tal forma que os conceitos com maior capacidade para facilitar aprendizagem subsequente sejam apresentados no início. Para ajudar na resposta a estas questões, achámos útil a técnica do mapa de conceitos. A fig. 2 mostra um mapa «macro» para algumas das ideias mais gerais em química orgânica e a fig. 3 mostra um mapa "micro" representando conceitos mais específicos (menos gerais) e reacçð̄es exemplificativas. Instruções para a elaboração de mapas de conceitos foram já publicadas. (Stewart et al, 1979) (Moreira, 1979).

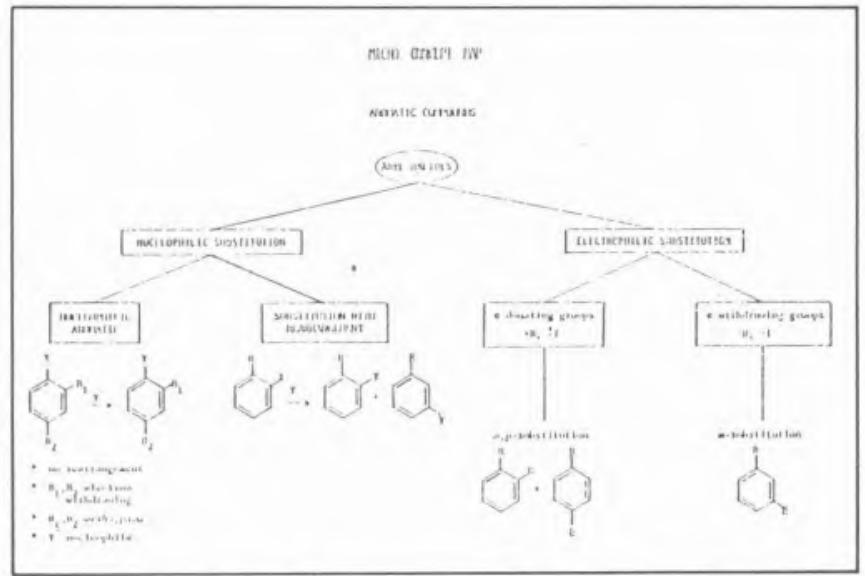

Fig. 2. Um mapa umicron de conceitos preparado por Atkin (1977) para planificaçào de guias de laboratório para quimica orgånica

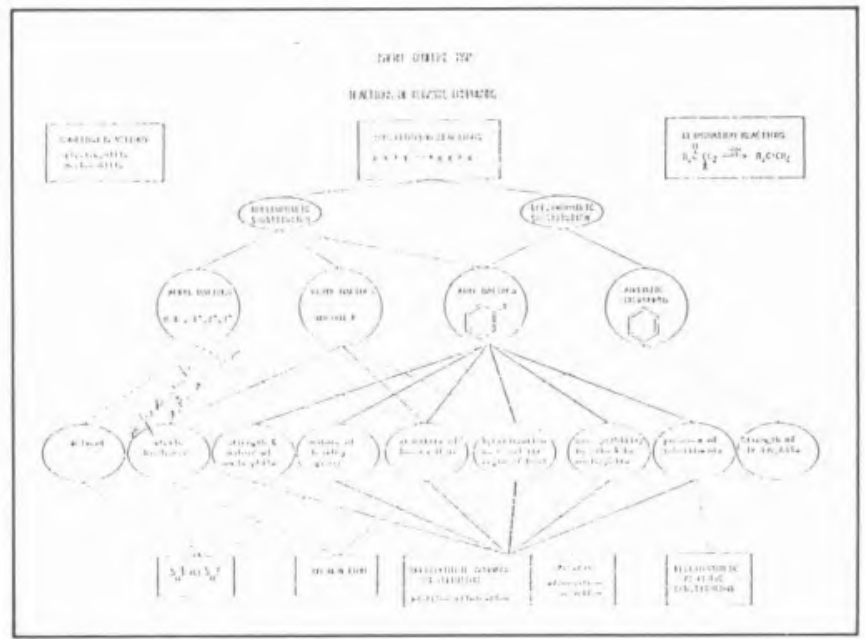

Fig. 3. Um mapa "macro" de conceitos mostrando conceitos mais especificos c exemplos ilustrativos (Atkins 1977)

Os mapas de conceitos são igualmente úteis se os alunos forem ensinados a construir os seus próprios mapas. Num projecto com alunos do ensino secundário geral (13-14 anos), mostrámos-lhes como «fazer um mapa" de uma secção dos seus livros de textos ou de experiências laboratoriais, construindo um mapa-exemplo no quadro ou no retroprojector. Os alunos foram então solicitados a constuir os seus próprios mapas, dos quais um é mostrado na fig. 4. Este foi o primeiro mapa construído pelo aluno e é um mapa superior à média. Cada mapa é naturalmente único e os alunos começam a aperceber-se que os significados de conceitos e de princípios variam. No entanto, eles podem notar pontos comuns nos mapas uns dos outros e também os pontos fortes e os pontos fracos.

Usámos mapas de conceitos com estudantes universitários em diversos cursos de ciências, mas até agora 




Fig. 4. Um mapa de conceitos construido por um aluno de Cièncias Fisicas 8. grau, numa primeira aproximaço

nenhum dos meus alunos utilizou esta técnica de modo sistemático com estudantes universitários de química.

Os mapas de conceitos auxiliam o professor a desenvolver uma espécie de mapa dos caminhos pelos quais a instrução pode seguir e a teoria de Ausubel sugere que é usualmente melhor partir do conceito mais geral, de maior conteúdo. Deste modo, os significados específicos dos conceitos subordinados podem ser integrados nas ideias de maior generalidade. De igual modo, as semelhanças e as diferenças entre conceitos subordinados necessitam ser clarificados mostrando relações entre conceitos relacionados e/ou diferentes na hierarquia. Ausubel (1978) apresenta os detalhes deste processo nas suas discussões dos princípios de diferenciação progressiva, reconciliação integrativa e aprendizagem de ordem superior mas esta discussão está além do âmbito deste texto. Para se tornar um professor eficiente, a aquisição da capacidade de construir mapas de conceitos para capítulos do seu curso é uma estratégia útil.

Ausubel é talvez melhor conhecido pelo seu conceito de organizador inicial. De modo a facilitar a ligação do novo conhecimento com o já existente, conceitos relevantes na estrutura cognitiva do aluno, Ausubel mostrou que uma curta tarefa educacional pode ser planificada a qual é mais geral e mais abstracta que o material que se segue e que tal tarefa serve como uma «ponte de conhecimento" ("cognitive bridge») entre a estrutura cognitiva que já existe no aluno e o novo e mais específico material de aprendizagem. West and Fensham (1976) mostraram que os organizadores iniciais facilitam a instrução em química. Tem sido feita muita pesquisa, e tem havido uma controvérsia considerável, sobre o valor potencial dos organizadores iniciais. Muitas das pesquisas têm sérias insuficiências metodológicas, mas os melhores estudos suportam claramente a posição de Ausubel.

Há muito mais para dizer acerca da aprendizagem com significado e da planificação da instrução; em «A
Theory of Education", tentei elaborar este tema de modo a ter significado para professores bem como para investigadores em educação. Agora desejo regressar ao assunto da epistemologia e a um meio heurístico muito útil recentemente inventado pelo meu colega $\mathrm{D}$. Bob Gowin. A fig. 5 mostra a estrutura geral do V de Gowin.

\section{Epistemological "v"}

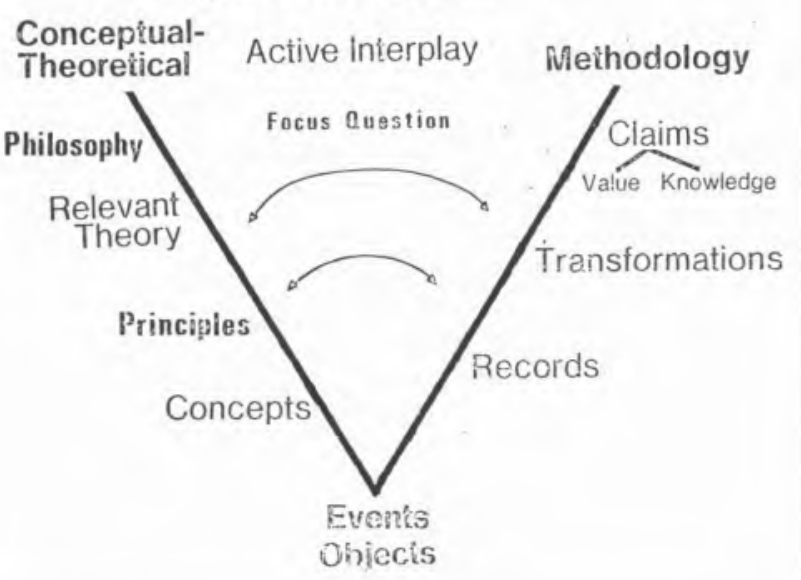

Fig. 5. V epistenológico de Gowin ilustrando elementos chave na estrutura do conhecimento. Os elementos do lado esquerdo (conceptuais) estâo activamente envolvidos com os elementos (conceptuais) estâo activamente

No «ponto».do V está aquilo de que o mundo é feito - objectos e acontecimentos - e são estes objectos e acontecimentos que estudamos para encontrar regularidades. Inventamos conceitos quando encontramos novas regularidades, e por outro lado os nossos conceitos guiam-nos na selecção de objectos e de acontecimentos a observar e a registar. Em muitos estudos laboratoriais (incluindo muitos realizados por candidatos a Ph. D.), os estudantes estão ocupados a registar e a transformar registos e estabelecendo conclusões (o que nós preferimos chamar reivindicações de conhecimentos). Infelizmente, os estudantes raramente conduzem as actividades metodológicas no lado direito do $\mathrm{V}$ de Gowin tendo conscientemente como base os conceitos, princípios e teorias do lado esquerdo de Gowin. O que falta é uma interacção consciente entre a «acção» («doing») e a "teoria» («thinking») na produção do conhecimento científico. Pior ainda, alguns estudantes não são capazes sequer de reconhecer que o conhecimento é produzido tal como a roupa ou os automóveis e não descoberto como o ouro ou o petróleo. É surpresa para muitos estudantes constatar que todo o conhecimento científico é construído a partir das reivindicações («claims») de numerosas pesquisas. Por vezes as reivindicações mudam.

Um dos meus alunos graduados, Bernardo Buchweitz,construíu mapas em $\mathrm{V}$ para todas as experiências sobre óptica num curso de física. A fig. 6 mostra um mapa para uma experiência. Buchweitz verificou que a construção de mapas em $\mathrm{V}$ para as experiências é um bom modo de detectar insuficiências nas experiências e nas instruções. Hai Hsia Chen (1979) verificou que estudantes de física que estudaram por manuais de laboratório reescritos após análise com o $\mathrm{V}$ de Gowin executaram as suas tarefas significativamente melhor que os alunos que usavam os manuais de laboratório "standart». Em química, bem como em biologia e física, os professores modificam ou substituem constantemente as expe- 


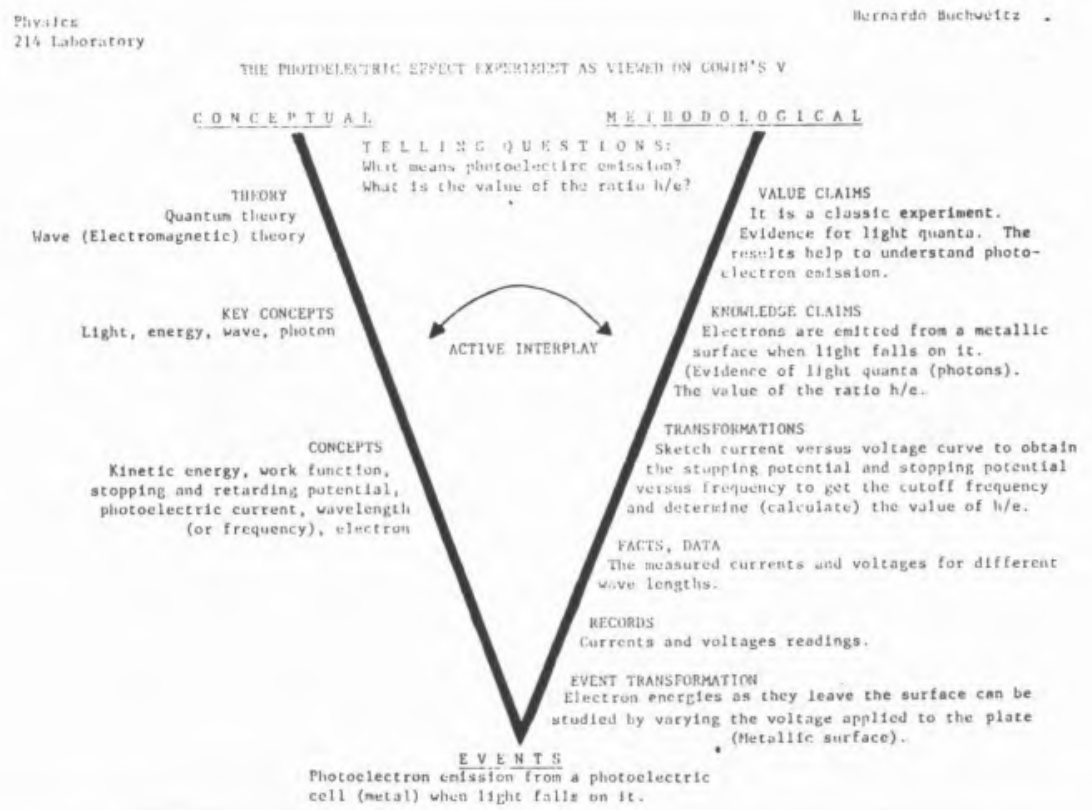

Fig. 6 - Um exercicio laboratorial esquematizado no $\mathbf{V}$ de Gowin flustrando os conceitos principais e os elementos metodológicos necessirios para compreender o que sucede quando a luz incide numa placa metalica. Necessitamos instrumentaçio que transforme o acontecimento e permita produzir registos

riências de laboratório, apenas para encontrar as mesmas deficiências frustrantes no trabalho subsequente dos seus alunos. A pesquisa de Chen sugere que é possível, usando o mapa de conceitos e o V de Gowin, analisar experiências e guias de laboratório de modo a conduzir a um sucesso quase uniforme pelos alunos. Além deste trabalho, não temos resultados semelhantes a indicar para química universitária. Aqui está uma área onde podem conduzir algumas pesquisas em educação.

Uma última técnica que eu acredito ser importante para todos os professores é a "entrevista clínica» ("clinical interview»). Jean Piaget popularizou o uso das entrevistas clínicas na sua monumental obra* nos seus esforços para estudar o desenvolvimento cognitivo da criança. Basicamente, a entrevista clínica é como um exame oral, excepto no facto de que é muitas vezes usada em conjunto com algum tipo de aparelhos ou diagramas.

Uma entrevista clínica cuidadosamente estruturada administrada a entre três e seis estudantes representativos pode ser um meio muito eficiente para obter melhor compreensão («insights») sobre quais os conceitos de que os alunos dispõem (ou as suas confusðes) e como eles os aplicam para interpretar um determinado fenómeno. Cerca de quinze a vinte minutos de entrevista clinica com alguns alunos fornecerão muitas vezes informações surpreendentes sobre as razões porque os alunos estão frustrados ou falharam num determinado exercício laboratorial ou problema escrito.

Em resumo, encontrámos quatro estratégias de ensino que são muito úteis aos alunos e/ou professores para facilitar a aprendizagem com significado: (1) elaboração de mapas de conceitos; (2) construção dos mapas epistemológicos do $\mathrm{V}$ de Gowin; (3) organizadores iniciais; e (4) entrevistas clínicas. Superficialmente, estas estratégias podem aparecer como simples artifício de ensino, mas nós acreditamos que, pelo contrário, são poderosas ferramentas de ensino-aprendizagem. Como todas as ferramentas, professores e alunos tornar-se-ão mais hábeis e sentir-se-ão mais á vontade á medida que as utilizarem e procurarem compreender a teoria da qual emergem.

(*) A teoria desenvolvimentista de Piaget é amplamente conhecida, mas eu acredito que a Teoria da Aprendizagem de Ausubel é mais potente e parsimoniosa para fins educacionais, como argumento noutro lado (Novak, 1977b).

\section{REFERÊNCIAS}

Atkin, Julia A. 1977. "An Information Processing Model of Learning and Problem Solving.n Ph. D. thesis, Cornell University. Ausubel, David P. 1963. The Psychology of Meaningful Verbal Learning. New York: Grune and Stratton.

, J. D. Novak and H. Hanesian. 1978. Educational Psychology: A Cognitive View. 2nd ed. New York: Holt, Rinehart and Winston.

Chen, Hai Hsia. 1979. «Relevance of Gowin's Structure of Knowledge and Ausubel's Learning Theory of Methods for Improving Physics Laboratory Instruction",. M. S, thesis, Cornell University.

Conant, James B. 1947. On Understanding Science. New Haven: Yale University Press.

Kuhn, Thomas S. 1962, 1970. The Structure of Scientific Revolutions. International Encyclopedia of Unified Sciences, 2nd ed. enlarged Vols. 1 and 2: Foundations of the Unity of Science, Vol. 2, No. 2. Chicago: University of Chicago Press.

Moreira, Marco. A. 1979. "Concept Maps as Tools for Teaching» Journal of College Teaching, 8(5), 283-286.

Novak, Joseph D. 1977a. A Theory of Education. Ithaca, New York: Cornell University Press. Science and Mathematics Education." Science Education, 71(4); 453-377. By the same title see Studies in Science Education, 5(1978), $1-30$.

Stewart, J., J. Van Kirk and R. Rowell. 1979. «Concept Maps: A Tool for Use in Biology Teaching." American Biology Teacher, 41(3), 171.

Toulmin, Stephen. 1972. Human Understanding, Vol 1: The Collective Use and Evolution of Concepts. Princeton: Princeton University Press.

West, L.H.T. \& Fensham, P. J. «Prior Knowledge or Advanced Organizers as Effective Variables in Chemical Learning." Journal of Research in Science Teaching, 13, 297-306, 1976.

Wiener, Norbert. 1948. Cybernetics. New York: Wiley.

N , 1954. The Human Use of Human Beings. 2d ed. Garden City, N.Y.: Doubleday. 